\section{Comments on paper by Dunham}

\author{
BARBARA HERRING \\ University of Toronto, Toronto, Ontario \\ MSS 1Al, Canada
}

Dunham (1978) stated that his present and past research is a challenge to the argument that it is necessary to consider the functional relevance of behaviors if we wish to predict the effects of aversive stimulation on those patterns of behavior (e.g., Bolles, 1970; Shettleworth, 1972; Walters \& Glazer, 1971). However, the research presented by Dunham does not appear to constitute an adequate test of such a statement.

\section{Suppression of All Categories of Behavior?}

The first generalization made by Dunham is that all categories of behavior can be suppressed by punishment. In order to support such a statement, it would be necessary to punish responses from different categories and demonstrate the same basic punishment effects on each category. While Dunham has punished several behaviors, he can hardly claim to have punished a variety of functional categories of behavior. In his first experiment (Dunham, 1971), he punished eating, drinking, and paper shredding in gerbils; in his second (Dunham, 1972), he punished drinking in rats; and in his latest experiments (Dunham, 1978), he punished eating in gerbils. In summary, except in one instance of paper-shredding, all the responses punished could be termed consummatory responses.

Thus he has chosen a category which may be particularly susceptible to suppression by punishment (Walters \& Herring, 1978), as compared to leverpressing, while neglecting the category of speciesspecific defense reactions, which are those claimed to be refractory to the effects of punishment (Bolles, 1970). His data that consummatory and nest-building behaviors can be suppressed by punishment presents no challenge to and would be compatible with generalizations such as Bolles' (1970) or Walters and Glazers' (1971).

\section{Increase in the Most Frequent Unpunished Response?}

Dunham's second generalization was that the most frequent unpunished response increases when the punished response is suppressed. An adequate test of such a claim would be to punish different behavior categories and observe various other categories which are not punished. In addition, it would be useful to know the unconditioned effects of the aversive stimulus in the environment in order to claim that the shock contingency was a necessary factor. Dunham provided little data on either of these tests. His first experiment (Dunham, 1971), in which he punished each of the three behaviors in turn and observed the change in the other two (unpunished) behaviors, was an adequate test of the first requirement for those three behaviors. The other experiments (Dunham, 1972, 1978) cited as support for his second generalization all used wheel running as the most frequent unpunished response, and always punished a consummatory response. In order to generalize as Dunham did, he would also have had to punish running, to determine if that would result in an increase in a consummatory response (assuming the consummatory response was the most frequent unpunished response). I doubt whether the latter result would be found. Since running is considered a species-specific defense reaction in rats and gerbils, it might be expected to increase rather than decrease when it is followed by contingent shock.

At least, it is likely that the shock contingency was not necessary to suppress consummatory behavior and increase running in Dunham's experiments. Extensive research by Amsel and his co-workers (e.g., Amsel \& Cole, 1953) indicated that drinking was suppressed in the presence of stimuli associated with shock. Other studies (e.g., Goodman, Dyal, Zinser, $\&$ Golub, 1966) have reported that running increased in the presence of noncontingent aversive stimulation. Thus it is quite possible that the behavioral changes noted by Dunham (1978) as support for his second rule of punishment were, in fact, due to the aversion stimulation per se and not to the punishment contingency.

In summary, the generalizations made by Dunham (1978) that the punished response is suppressed by punishment and that the most frequent unpunished response increases are not adequately tested by his data. This is particularly disappointing since, with the use of more diverse functional categories of behavior and with control conditions to rule out noncontingent shock effects, Dunham's methodology might have resulted in a significant contribution to the interesting problems of punishment that he addressed.

\section{REFERENCES}

Amsel, A., \& Cole, K. F. Generalization of fear motivated interference with water intake. Journal of Experimental Psychology, 1953, 46, 243-247.

Bolles, R. C. Species-specific defense reactions and avoidance learning. Psychological Review, 1970, 77, 32-48.

Dunham, P. J. Punishment: Method and theory. Psychological Review, 1971, 78, 58-70.

Dunham, P. J. Some effects of punishment upon unpunished 
responding. Journal of the Experimental Analysis of Behavior, $1972,17,443-450$.

Dunham, P. J. Changes in unpunished responding during response-contingent punishment. Animal Learning \& Behavior, 1978, 6, 174-180.

Goodman, E. D., Dyal, J. A., Zinser, O., \& Golub, A. UCR morphology and shock intensity. Psychonomic Science, 1966, $5,431-432$.

ShettLEworth, S. J. Constraints on learning. In D. S. Lehrman, R. A. Hinde, \& E. Shaw (Eds.), Advances in the study of behavior (Vol. 4). New York: Academic Press, 1972.

Walters, G. C., \& Glazer, R. D. Punishment of instinctive behavior in the Mongolian gerbil. Journal of Comparative and Physiological Psychology, 1971, 75, 331-340.

Walters, G. C., \& Herring, B. Differential suppression by punishment of nonconsummatory licking and lever pressing. Journal of Experimental Psychology: Animal Behavior Processes, 1978, 4, 170-187.

(Received for publication October 2, 1978; accepted November 13,1978 .) 